\title{
Fungal infection-related mortality versus total mortality as an outcome in trials of antifungal agents Anne K Due ${ }^{\dagger}$, Helle K Johansen and Peter C Gøtzsche*†
}

\author{
Address: Nordic Cochrane Centre, Rigshospitalet, Dept. 7112, Blegdamsvej 9, DK-2100 København Ø, Denmark \\ Email: Anne K Due - anne.k.due@sol.dk; Helle K Johansen - hkj@cochrane.dk; Peter C Gøtzsche* - pcg@cochrane.dk \\ * Corresponding author †Equal contributors
}

Published: 14 August 2006

BMC Medical Research Methodology 2006, 6:40 doi:10.1186/147|-2288-6-40

This article is available from: http://www.biomedcentral.com/I47/-2288/6/40

(C) 2006 Due et al; licensee BioMed Central Ltd.

This is an Open Access article distributed under the terms of the Creative Commons Attribution License (http://creativecommons.org/licenses/by/2.0), which permits unrestricted use, distribution, and reproduction in any medium, provided the original work is properly cited.
Received: 0I November 2005

Accepted: 14 August 2006

\begin{abstract}
Background: Disease specific mortality is often used as outcome rather than total mortality in clinical trials. This approach assumes that the classification of cause of death is unbiased. We explored whether use of fungal infection-related mortality as outcome rather than total mortality leads to bias in trials of antifungal agents in cancer patients.

Methods: As an estimate of bias we used relative risk of death in those patients the authors considered had not died from fungal infection. Our sample consisted of 69 trials included in four systematic reviews of prophylactic or empirical antifungal treatment in patients with cancer and neutropenia we have published previously.

Results: Thirty trials met the inclusion criteria. The trials comprised 6130 patients and 869 deaths, $220(25 \%)$ of which were ascribed to fungal infection. The relative risk of death was $0.85(95 \% \mathrm{Cl}$ $0.75-0.96)$ for total mortality, 0.57 (95\% Cl 0.44-0.74) for fungal mortality, and $0.95(95 \% \mathrm{Cl} 0.82-$ I.09) for mortality among those who did not die from fungal infection.

Conclusion: We could not support the hypothesis that use of disease specific mortality introduces bias in antifungal trials on cancer patients as our estimate of the relative risk for mortality in those who survived the fungal infection was not increased. We conclude that it seems to be reliable to use fungal mortality as the primary outcome in trials of antifungal agents. Data on total mortality should be reported as well, however, to guard against the possible introduction of harmful treatments.
\end{abstract}

\section{Background}

Disease specific mortality is often used as outcome rather than total mortality in clinical trials. This approach assumes that the classification of cause of death is unbiased. However, a comparison of noncancer death rates in cancer patients with noncancer death rates in a matched population showed that use of cancer specific mortality may underestimate the mortality related to cancer, and that treatment-related deaths seemed to have been omit- ted from cancer mortality [1]. A review of cancer screening trials also identified inconsistencies between disease specific mortality and all-cause mortality [2], and it has been shown that biased misclassification of cause of death can give a spurious advantage to aggressive cancer treatments over less aggressive treatments [3].

For antifungal agents, a higher incidence of bacterial infections has been reported which might be a class effect 
related to the azole drugs [4], and itraconazole is associated with congestive heart failure [5]. As aggressive treatment may increase mortality due to treatment but decrease mortality due to the disease in question, bias in classification of cause of death may influence the results of the trials. According to the recommendations of the CONSORT Group all deaths should be reported regardless of cause [6].

In this study we explored whether use of fungal infectionrelated mortality as outcome rather than total mortality leads to bias in trials of antifungal agents in cancer patients. Most patients with invasive fungal infection are suffering from severe underlying conditions [7], and as fungal infections are difficult to diagnose, misclassification of cause of death may occur. Accordingly, in autopsy studies many patients were considered to have died from a fungal infection that was not suspected or confirmed antemortem [8].

\section{Methods}

We used a sample consisting of trials included in 4 systematic reviews concerning prophylactic or empirical treatment in patients with cancer and neutropenia at risk for fungal infections, which we have published previously [4,9-11]. According to our protocol, trials had to be randomised, published as full papers, include mainly cancer patients and report on at least one fungal death and one death from another cause to be included in the study. Details on overall mortality and disease specific mortality were extracted by two persons independently and disagreements were resolved by discussion. Data were analysed as relative risks [12] and 95\% confidence intervals (CI) are presented. A fixed effect model was used since there was very little heterogeneity between the studies.

As an estimate of bias we used relative risk of death in those patients the authors considered had not died from fungal infection. Provided the two groups are still comparable after subtraction of fungal deaths from those randomised, the proportion of those who died from another cause than fungal infection would be expected to be the same in the two groups (fig. 1a). If, however, there was a bias in classification of cause of death in favour of the treated group, fewer deaths would be ascribed to fungal infection and more deaths to other causes in this group. This would result in a larger relative risk of death for those who did not die from fungal infection (fig. 1b).

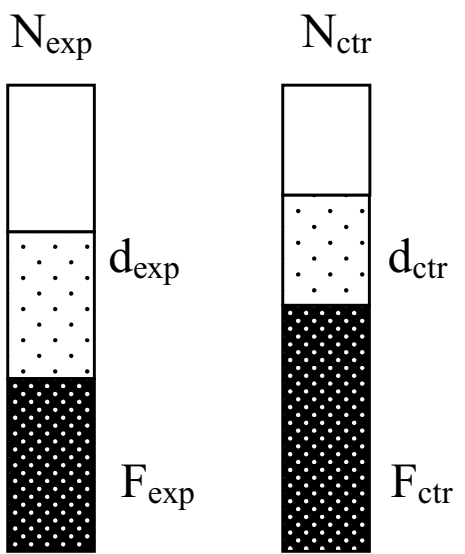

Fig. 1a

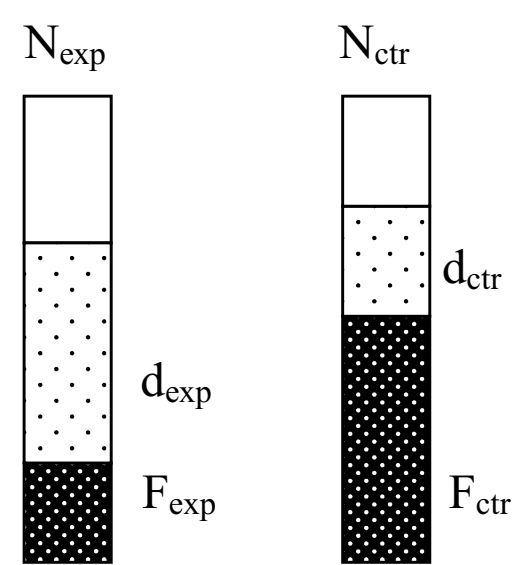

Fig. 1b

\section{Figure I}

Relative risk of death from causes other than fungal infection in those who survived the fungal infection. Provided the two groups are still comparable after subtraction of fungal deaths from those randomised, the proportion of those who died from another cause than fungal infection would be expected to be the same in the two groups (fig. Ia). If, however, there was a bias in classification of cause of death in favour of the treated group, fewer deaths would be ascribed to fungal infection and more deaths to other causes in this group. This would result in a larger relative risk of death for those who did not die from fungal infection (fig. Ib). This risk is an estimate of bias overall: $R R=\left(d_{\text {exp }} /\left(N_{\text {exp }}-F_{\text {exp }}\right)\right) /\left(d_{c t r} /\left(N_{c t r}-F_{c t r}\right)\right)$, where exp: experimental group; ctr: control group; $N_{\text {exp }}, N_{c t r}$ : numbers of randomised patients; $F_{\text {exp }}, F_{c t r}$ : numbers of deaths from fungal infection; $d_{\text {exp }}, d_{c t r}$ : numbers of deaths from causes other than fungal infection. 


\section{Results}

Our sample consisted of 69 trials [13-81] 30 of which met the inclusion criteria [13-42]. Thirty-one trials were excluded as they did not report the necessary mortality data, 4 were published as abstracts and in 4 trials the patients did not have cancer. The interventions were no treatment, placebo, amphotericin B, fluconazole, miconazole, itraconazole and nystatin. In all trials that compared two drugs, it was easy to decide which was the experimental one and which was the control drug.

The trials comprised 6130 patients and 869 deaths, 220 (25\%) of which were ascribed to fungal infection. The relative risk of death was 0.85 (95\% CI 0.75-0.96) for total mortality, 0.57 (95\% CI 0.44-0.74) for fungal mortality, and 0.95 (95\% CI $0.82-1.09)$ for mortality among those who did not die from fungal infection (see additional files 1, 2, 3 for graphs and data extracted from the studies).

\section{Discussion}

We could not support the hypothesis that use of disease specific mortality introduces bias in antifungal trials on cancer patients as our estimate of the relative risk for mortality in those who survived the fungal infection was not increased. We had expected some increase, even in the absence of any misclassification bias, since, in case of positive treatment effects, more severely ill patients would survive in the experimental group which would be expected to increase their risk of death, compared with surviving patients in the control group. It should be noted, however, that the confidence interval for our risk estimate, $0.82-1.09$, is compatible with the possible existence of minor bias.

Subgroup analyses should generally be discouraged when a null hypothesis of no difference (no bias in our case) could not be rejected. However, we did an exploratory analysis where we included only those trials that were not blinded since the risk of bias is largest in these trials. The total number of deaths among those who survived the fungal infection was 255, as compared with 649 for the corresponding analysis for all the trials. The relative mortality risk among those who did not die from fungal infection was 0.90 (95\% CI $0.72-1.14)$, which is very similar to our estimate of 0.95 (95\% CI $0.82-1.09)$ for all the trials.

\section{Conclusion}

We conclude that it seems to be reliable to use fungal mortality as the primary outcome in trials of antifungal agents. Data on total mortality should be reported as well, however, to guard against the possible introduction of harmful treatments as we cannot know whether our findings will apply to future antifungal agents.

\section{Competing interests}

The author(s) declare that they have no competing interests.

\section{Authors' contributions}

PCG conceived the study; AKD wrote the draft protocol and manuscript; all authors contributed to data extraction, writing the protocol and the manuscript, and approved the final manuscript.

\section{Additional material}

\section{Additional file 1 \\ Total mortality Graph and details on the computation of RR for total mortality \\ Click here for file \\ [http://www.biomedcentral.com/content/supplementary/1471- 2288-6-40-S1.jpeg]}

\section{Additional file 2}

Fungal mortality Graph and details on the computation of $R R$ for mortality from fungal infection

Click here for file

[http://www.biomedcentral.com/content/supplementary/1471-

2288-6-40-S2.jpeg]

\section{Additional file 3}

Other mortality in survivors of fungal infection Graph and details on the computation of RR for mortality in patients classified as not dying from fungal infection

Click here for file

[http://www.biomedcentral.com/content/supplementary/14712288-6-40-S3.jpeg]

\section{References}

I. Brown BW, Brauner C, Minotte MC: Noncancer deaths in white adult cancer patients. J Natl Cancer Inst 1993, 85:979-87.

2. Black WC, Haggstrom DA, Welch HG: All-cause mortality in randomized trials of cancer screening. J Natl Cancer Inst 2002, 94:167-73.

3. Newschaffer CJ, Otani K, McDonald MK, Penberthy LT: Causes of death in elderly prostate cancer patients and in a comparison nonprostate cancer cohort. I Natl Cancer Inst 2000, 92(8):6|3-2|.

4. Gøtzsche PC, Johansen HK: Routine versus selective antifungal administration for control of fungal infections in patients with cancer. Cochrane Database Syst Rev 2002:CD000026.

5. Ahmad SR, Singer SJ, Leissa BG: Congestive heart failure associated with itraconazole. Lancet 200I, 357(9270): I766-7.

6. loannidis JPA, Evans SJW, Gøtzsche PC, O'Neill RT, Altman DG, Schultz K, Moher D, for the CONSORT Group: Better Reporting of Harms in Randomized Trials: An Extension of the CONSORT Statement. Annals of Internal Medicine 2004, I4I(10):78I-788.

7. Groll AH, Shah PM, Mentzel C, Schneider M, Just-Nuebling G, Huebner $\mathrm{K}$ : Trends in the postmortem epidemiology of invasive fungal infections at a university hospital. Journal of infection 1996, 33:23-32.

8. Vogeser M, Wanders A, Haas A, Ruckdeschel G: A four-year review of fatal aspergillosis. European Journal of clinical microbiology and infectious diseases 1999, 18:42-45. 
9. Johansen HK, Gøtzsche PC: Amphotericin B versus fluconazole for controlling fungal infections in neutropenic cancer patients. Cochrane Database Syst Rev 2002:CD000239.

10. Gøtzsche PC, Johansen HK: Nystatin prophylaxis and treatment in severely immunodepressed patients. Cochrane Database Syst Rev 2002:CD002033.

II. Johansen HK, Gøtzsche PC: Amphotericin B lipid soluble formulations vs amphotericin $B$ in cancer patients with neutropenia. Cochrane Database Syst Rev 2000:CD000969.

12. Review Manager (RevMan) [Computer program]. In Version 4.2 for Windows Copenhagen: The Nordic Cochrane Centre, The Cochrane Collaboration; 2003.

13. Akiyama H, Mori S, Tanikawa S, Sakamaki H, Onozawa Y: Fluconazole versus oral amphotericin $B$ in preventing fungal infection in chemotherapy-induced neutropenic patients with haematological malignancies. Mycoses 1993, 36:373-8.

14. Anaissie EJ, Darouiche RO, Abi Said D, Uzun O, Mera J, Gentry LO, Williams T, Kontoyiannis DP, Karl CL, Bodey GP: Management of invasive candidal infections: results of a prospective, randomized, multicenter study of fluconazole versus amphotericin B and review of the literature. Clinical infectious diseases: an official publication of the Infectious Diseases Society of America 1996, 23:964-72.

15. Bodey GP, Anaissie EJ, Elting LS, Estey E, O'Brien S, Kantarjian H: Antifungal prophylaxis during remission induction therapy for acute leukemia fluconazole versus intravenous amphotericin B. Cancer 1994, 73:2099-106.

16. Ellis ME, Clink H, Ernst P, Halim MA, Padmos A, Spence D, Kalin M, Hussain Qadri SM, Burnie J, Greer W: Controlled study of fluconazole in the prevention of fungal infections in neutropenic patients with haematological malignancies and bone marrow transplant recipients. European Journal of Clinical Microbiology \& Infectious Diseases 1994, 13:3-II.

17. EORTC International Antimicrobial Therapy Cooperative Group: Empiric antifungal therapy in febrile granulocytopenic patients. The American journal of medicine 1989, 86:668-72.

18. Goldstone AH, O'Driscoll A: Early AmBisome in febrile neutropenia in patients with haematological disorders. Bone Marrow Transplant 1994, I4(Suppl 5):SI5-7.

19. Goodman JL, Greenfield R, Buell D: Prophylactic fluconazole and marrow transplantation. The New England journal of medicine 1992, 327:645.

20. Kelsey SM, Goldman JM, McCann S: Liposomal amphotericin (AmBisome) in the prophylaxis of fungal infections in neutropenic patients: a randomised, double-blind, placebo-controlled study. Bone Marrow Transplant 1999, 23(2): 163-8.

21. Kern W, Behre G, Rudolf T: Failure of fluconazole prophylaxis to reduce mortality or the requirement of systemic amphotericin B therapy during treatment for refractory acute myeloid leukemia: results of a prospective randomized phase III study. In Cancer Volume 83. German AML Cooperative Group; | 1998:291-301.

22. Leenders AC, Daenen S, Jansen RL, Hop WC, Lowenberg B, Wijermans PW: Liposomal amphotericin B compared with amphotericin $B$ deoxycholate in the treatment of documented and suspected neutropenia-associated invasive fungal infections. British Journal of Haematology 1998, 103(I):205-12.

23. Menichetti F, Del Favero A, Martino P, Bucaneve G, Micozzi A D'Antonio D, Ricci P, Carotenuto M, Liso V, Nosari AM, Barbui T, Fasola G, Mandelli F, GIMEMA Infection Program: Preventing fungal infection in neutropenic patients with acute leukemia: fluconazole compared with oral amphotericin B. The GIMEMA Infection Program. Annals of internal medicine 1994, I20:9|3-8.

24. Menichetti F, Del Favero A, Martino P: Itraconazole oral solution as prophylaxis for fungal infections in neutropenic patients with hematologic malignancies: a randomized, placebo-controlled, double-blind, multicenter trial. GIMEMA Infection Program. Gruppo Italiano Malattie Ematologiche dell' Adulto. Clinical infectious diseases: an official publication of the Infectious Diseases Society of America 1999, 28(2):250-5.

25. Meunier F, Aoun M, Janssens M, Dekoster C, Paesmans M: Chemoprophylaxis of fungal infections in granulocytopenic patients using fluconazole vs oral amphotericin B. Drug Investigation $1991,3: 258-65$
26. Nucci M, Biasoli I, Akiti T, Silveira F, Solza C, Barreiros G: A doubleblind, randomized, placebo-controlled trial of itraconazole capsules as antifungal prophylaxis for neutropenic patients. Clinical infectious diseases: an official publication of the Infectious Diseases Society of America 2000, 30(2):300-5.

27. Perfect JR, Klotman ME, Gilbert CC: Prophylactic intravenous amphotericin $B$ in neutropenic autologous bone marrow transplant recipients. The Journal of infectious diseases 1992 , | 65(5):89|-7.

28. Pizzo PA, Robichaud KJ, Gill FA, Witebsky FG: Empiric antibiotic and antifungal therapy for cancer patients with prolonged fever and granulocytopenia. The American journal of medicine 1982, 72(I): I0I-II.

29. Rotstein C, Bow EJ, Laverdiere M, loannou S, Carr D, Moghaddam N: Randomized placebo-controlled trial of fluconazole prophylaxis for neutropenic cancer patients benefit based on purpose and intensity of cytotoxic therapy. The Canadian Fluconazole Prophylaxis Study Group. Clinical infectious diseases: an official publication of the Infectious Diseases Society of America 1999 , 28(2):33।-40.

30. Schaffner A, Schaffner M: Effect of prophylactic fluconazole on the frequency of fungal infections, amphotericin $B$ use, and health care costs in patients undergoing intensive chemotherapy for hematologic neoplasias. The Journal of infectious diseases 1995, I72(4): I035-4I.

31. Schoffski P, Freund M, Wunder R, Petersen D, Kohne CH, Hecker H Safety and toxicity of amphotericin $B$ in glucose $5 \%$ or intralipid $20 \%$ in neutropenic patients with pneumonia or fever of unknown origin: randomised study. BM] 1998 3 I 7(7I 55):379-84

32. Silling G, Fegeler W, Roos N, Essink M, Büchner T: Early empiric antifungal treatment of infections in neutropenic patients comparing fluconazole with amphotericin B/flucytosine. Mycoses 1999, 42(Suppl 2): I0I-4.

33. Slavin MA, Osborne B, Adams R, Levenstein M, Schoch HG, Feldman $A R$ : Efficacy and safety of fluconazole prophylaxis for fungal infections after marrow transplantation - a prospective, randomized, double-blind study. The Journal of infectious diseases |995, I 7 I(6): I545-52.

34. Suda T, Omine M, Tsuchiya J, Maekawa T, Muto Y, Mizoguchi H: [A co-operative study on prophylaxis of fungal infection in patients with hematological diseases: prophylactic effect of oral administration of amphotericin B] [Japanese]. [Rinsho Ketsueki] The Japanese journal of clinical hematology 1980, 2 I (2): 195-9.

35. Tollemar J, Ringden O, Andersson S, Sundberg B, Liungman P, Tyden G: Randomized double-blind study of liposomal amphotericin B (Ambisome) prophylaxis of invasive fungal infections in bone marrow transplant recipients. Bone Marrow Transplantation 1993, 12(6):577-82.

36. Vreugdenhil G, Van Dijke BJ, Donnelly JP, Novakova IRO, Raemaekers JMM, Hoogkamp-Korstanje MAA: Efficacy of itraconazole in the prevention of fungal infections among neutropenic patients with hematologic malignancies and intensive chemotherapy. A double blind, placebo controlled study. Leukemia \& lymphoma 1993, II(5-6):353-8.

37. Walsh TJ, Finberg RW, Arndt C, Hiemenz I Schwartz C, Bodensteiner D: Liposomal amphotericin B for empirical therapy in patients with persistent fever and neutropenia. National Institute of Allergy and Infectious Diseases Mycoses Study Group. The New England Journal of Medicine 1999, 340(10):764-7I.

38. White MH, Bowden RA, Sandler ES, Graham ML, Noskin GA, Wingard JR: Randomized, double-blind clinical trial of amphotericin B colloidal dispersion vs. amphotericin B in the empirical treatment of fever and neutropenia. Clinical Infectious Diseases: an official publication of the Infectious Diseases Society of America 1998 , 27(2):296-302.

39. Wingard JR, Vaughan WP, Braine HG, Merz WG, Saral R: Prevention of fungal sepsis in patients with prolonged neutropenia: a randomized, double-blind, placebo-controlled trial of intravenous miconazole. The American journal of medicine 1987 83(6): $1103-10$.

40. Winston DJ, Hathorn JW, Schuster MG, Schiller GJ, Territo MC: A multicenter, randomized trial of fluconazole versus amphotericin B for empiric antifungal therapy of febrile neutropenic patients with cancer. The American journal of medicine 2000 108:282-9. 
4I. Wolff SN, Fay J, Stevens D, Herzig RH, Pohlman B, Bolwell B, Lynch J, Ericson S, Freytes CO, LeMaistre F, Collins R, Pineiro L, Greer J, Stein R, Goodman SA, Dummer S: Fluconazole vs low-dose amphotericin $B$ for the prevention of fungal infections in patients undergoing bone marrow transplantation: a study of the North American Marrow Transplant Group. Bone Marrow Transplant 2000, 25(8):853-9.

42. Young GA, Bosly A, Gibbs DL, Durrant S: A double-blind comparison of fluconazole and nystatin in the prevention of candidiasis in patients with leukaemia. Antifungal Prophylaxis Study Group. European Journal of Cancer 1999, 35(8): I208-13.

43. Acuna G, Winston DJ, Young LS: Ketoconazole prophylaxis of fungal infections in the granulocytopenic patient: a doubleblind, randomized controlled trial. In Program and Abstracts of 22nd Interscience Conference on Antimicrobial Agents and Chemotherapy American Society for Microbiology; 198I. [abstract] 852

44. Benhamou E, Hartmann O, Nogues C, Maraninchi D, Valteau D, Lemerle J: Does ketoconazole prevent fungal infection in children treated with high dose chemotherapy and bone marrow transplantation? Results of a randomized placebocontrolled trial. Bone Marrow Transplant 199|, 7(2): |27-3|.

45. Brammer KW: Management of fungal infection in neutropenic patients with fluconazole. Hamatologie und Bluttransfusion 1990, 33:546-50.

46. Brincker $\mathrm{H}$ : Prophylactic treatment with miconazole in patients highly predisposed to fungal infection. A placebocontrolled double-blind study. Acta medica Scandinavica 1978, 204(I-2): I 23-8.

47. Brincker $\mathrm{H}$ : Prevention of mycosis in granulocytopenic patients with prophylactic ketoconazole treatment. Mykosen 1983, 26(5):242-7.

48. Buchanan AG, Riben PD, Rayner EN, Parker SE, Ronald AR, Louie T): Nystatin prophylaxis of fungal colonization and infection in granulocytopenic patients: correlation of colonization and clinical outcome. Clin Invest Med 1985, 8: 139-47.

49. Caillot D, Reny G, Solary E, Casasnovas O, Chavanet P, Bonnotte B: A controlled trial of the tolerance of amphotericin $B$ infused in dextrose or in Intralipid in patients with haematological malignancies. The Journal of Antimicrobial Chemotherapy 1994, 33(3):603-13.

50. Caselli D, Arico M, Michelone G, Cavanna C, Nespoli L, Burgio GR: Antifungal chemoprophylaxis in cancer children: a prospective randomized controlled study. Microbiologica 1990, | 3:347-51.

5I. Egger T, Gratwohl A, Tichelli A, Uhr M, Stebler Gysi C, Passweg J, Pless M, Wernli M, Buser U, Wuhrmann J, Frei R, Nissen C, Speck B: Comparison of fluconazole with oral polyenes in the prevention of fungal infections in neutropenic patients. A prospective, randomized, single-center study. Supportive Care in Cancer 1995, 3:139-46.

52. Epstein JB, Vickars L, Spinelli J, Reece D: Efficacy of chlorhexidine and nystatin rinses in prevention of oral complications in leukemia and bone marrow transplantation. Oral Surgery, Oral Medicine, and Oral Pathology 1992, 73:682-9.

53. Estey E, Maksymiuk A, Smith T, Fainstein V, Keating M, McCredie KB: Infection prophylaxis in acute leukemia. Comparative effectiveness of sulfamethoxazole and trimethoprim, ketoconazole, and a combination of the two. Archives of internal medicine 1984, I 44(8): I 562-8.

54. Feusner J, Robinson P, Seibel N, Reaman G, Waskerwitz M, Thompson C: Fluconazole (FLU) vs nystatin (NYS) for the prevention of fungal infection in neutropenic children receiving cytotoxic chemotherapy. Proceedings of the Annual Meeting of the American Society of Clinical Oncology 1994, 13:. [Abstract] A 1533, p. 444

55. Flynn PM, Cunningham CK, Kerkering T, San Jorge AR, Peters VB, Pitel PA, Harris J, Gilbert G, Castagnaro L, Robinson P: Oropharyngeal candidiasis in immunocompromised children: a randomized, multicenter study of orally administered fluconazole suspension versus nystatin. The Multicenter Fluconazole Study Group. J Pediatr 1995, 1 27:322-8.

56. Fukuda M, Hirashima K, Kurane R, Abe T, Sampi K, Tominaga K: [Empiric therapy with fluconazole in granulocytopenic patients with carcinoma or leukemia] [Japanese]. The Japanese journal of antibiotics 1994, 47(8): 1065-70.
57. Groll AH, Just-Nuebling G, Kurz M, Mueller C, Nowak-Goettl U, Schwabe D, Shah PM, Kornhuber B: Fluconazole versus nystatin in the prevention of candida infections in children and adolescents undergoing remission induction or consolidation chemotherapy for cancer. The Journal of Antimicrobial Chemotherapy 1997, 40:855-62.

58. Hansen RM, Reinerio N, Sohnle PG, Abrams RA, Ritch PS, Libnoch JA: Ketoconazole in the prevention of candidiasis in patients with cancer. A prospective, randomized, controlled, doubleblind study. Archives of internal medicine 1987, 147(4):710-2.

59. Hughes WT, Bartley DL, Patterson GG, Tufenkeji H: Ketoconazole and candidiasis: a controlled study. The Journal of Infectious diseases 1983, 147(6): 1060-3.

60. Lake DE, Kunzweiler J, Beer M, Buell DN, Islam MZ: Fluconazole versus amphotericin $B$ in the treatment of esophageal candidiasis in cancer patients. Chemotherapy 1996, 42:308-14.

6I. Lumbreras C, Cuervas-Mons V, Jara P, del Palacio A, Turrion VS, Barrios C, Moreno E, Noriega AR, Paya CV: Randomized trial of fluconazole versus nystatin for the prophylaxis of Candida infection following liver transplantation. The Journal of Infectious Diseases 1996, 174:583-8.

62. Malik IA, Moid I, Aziz Z, Khan S, Suleman M: A randomized comparison of fluconazole with amphotericin $B$ as empiric antifungal agents in cancer patients with prolonged fever and neutropenia. The American journal of medicine 1998, 105(6):478-83.

63. Marie JP, Lapierre V, Pico J, Vekhoff A, Molina L, Andremont A, Basset D, Lebeau B, Michalet M, Zittoun R, Hayat M, pour le Groupe d'Etude des Aplasies Fébriles (G.A.F.): Etude multicentrique randomisée fluconazole iv versus amphotéricine $B$ iv chez le patient neutropénique et fébrile. Cah Oncol 1993, 2: I7I-3.

64. Moreau P, Milpied N, Fayette N, Ramee JF, Harousseau JL: Reduced renal toxicity and improved clinical tolerance of amphotericin B mixed with intralipid compared with conventional amphotericin B in neutropenic patients. The Journal of Antimicrobial Chemotherapy 1992, 30(4):535-4I.

65. Nath CE, Shaw PJ, Gunning R, McLachlan AJ, Earl JW: Amphotericin $B$ in children with malignant disease: a comparison of the toxicities and pharmacokinetics of amphotericin B administered in dextrose versus lipid emulsion. Antimicrob Agents Chemother 1999, 43(6): 1417-23.

66. Nucci M, Loureiro M, Silveira F, Casali AR, Bouzas LF, Velasco E: Comparison of the toxicity of amphotericin $B$ in $5 \%$ dextrose with that of amphotericin $B$ in fat emulsion in a randomized trial with cancer patients. Antimicrob Agents Chemother 1999, 43(6): | $445-8$

67. Ninane J: A multicentre study of fluconazole versus oral polyenes in the prevention of fungal infection in children with hematological or oncological malignancies. Multicentre Study Group. European journal of clinical microbiology \& infectious diseases: official publication of the European Society of Clinical Microbiology 1994, 13:330-7.

68. Palmblad J, Lönnqvist B, Carlsson B, Grimfors G, Järnmark M, Lerner $R$ : Oral ketoconazole prophylaxis for Candida infections during induction therapy for acute leukaemia in adults: more bacteraemias. Journal of Internal medicine 1992, 23 I (4):363-70.

69. Pascual B, Ayestaran A, Montoro JB, Oliveras J, Estibalez A, Julia A Administration of lipid-emulsion versus conventional amphotericin B in patients with neutropenia. The Annals of Pharmacotherapy 1995, 29( I 2): I 197-20 I.

70. Philpott-Howard JN, Wade Jj, Mufti GJ, Brammer KW, Ehninger G: Randomized comparison of oral fluconazole versus oral polyenes for the prevention of fungal infection in patients at risk of neutropenia. Multicentre Study Group. The Journal of antimicrobial chemotherapy I 993, 3 I(6):973-84.

7I. Pons V, Greenspan D, Lozada-Nur F, McPhail L, Gallant JE, Tunkel A, Johnson CC, McCarty J, Panzer H, Levenstein M, Barranco A, Green $S$ : Oropharyngeal candidiasis in patients with AIDS: randomized comparison of fluconazole versus nystatin oral suspensions. Clinical Infectious Diseases 1997, 24: 1 204-7.

72. Prentice HG, Hann IM, Herbrecht R, Aoun M, Kvaloy S, Catovsky D: A randomized comparison of liposomal versus conventional amphotericin B for the treatment of pyrexia of unknown origin in neutropenic patients. British Journal of Haematology 1997, 98(3):7II-8. 
73. Riley DK, Pavia AT, Beatty PG: The prophylactic use of low-dose amphotericin B in bone marrow transplant patients. The American journal of medicine 1994, 97(6):509-14.

74. Sandler ES, Mustafa MM, Tkaczewski I, Graham ML, Morrison VA, Green M: Use of amphotericin B colloidal dispersion in children. Journal of Pediatric Hematology/Oncology: official journal of the American Society of Pediatric Hematology/Oncology 2000, 22(3):242-6.

75. Savino JA, Agarwal N, Wry P, Policastro A, Cerabona T, Austria L: Routine prophylactic antifungal agents (clotrimazole, ketoconazole, and nystatin) in nontransplant/nonburned critically ill surgical and trauma patients. The Journal of Trauma 1994, 36:20-5.

76. Siegel M, Murphy M, Counts GW, Meyers JD: Prophylactic ketoconazole for the prevention of fungal infection in bone marrow transplant patients. In 23rd Interscience Conference of Antimicrobial Agents and Chemotherapy (ICAAC) American Society for Microbiology; 1982. [abstract] 166

77. Teshima H, Masaoka T, Hiraoka A, Miyazaki T, Imamura M, Kitabayashi $A$ : $A$ randomised study to compare oral fluconazole with oral amphotericin B for suppression of fungal flora and prevention of fungal infection in bone marrow transplantation recipients. Drug Evaluation (Konnichi No Ishoku) 1994, 7:535-42.

78. Tian D, Jian H, Cui X, Kan M, Xi J, Su L, Zhen S, Sao W, Li Y, Wang $\mathrm{T}$ : Prospective study of fluconazole in the prevention of fungal infections in neutropenic patients with acute leukemia and non-Hodgkins lymphoma. 20th International Congress of Chemotherapy, June 29 to July 3 1997, Sydney, Australia 1997, 87:. [abstract] 3246

79. Viscoli C, Castagnola E, Van Lint MT, Moroni C, Garaventa A, Rossi MR, Fanci R, Menichetti F, Caselli D, Giacchino M, Congiu M: Fluconazole versus amphotericin $B$ as empirical antifungal therapy of unexplained fever in granulocytopenic cancer patients: a pragmatic, multicentre, prospective and randomised clinical trial. European Journal of Cancer 1996, 32A(5):8|4-20.

80. Winston DJ, Chandrasekar PH, Lazarus HM, Goodman JL, Silber JL, Horowitz $\mathrm{H}$ : Fluconazole prophylaxis of fungal infections in patients with acute leukemia. Results of a randomized placebo-controlled, double-blind, multicenter trial. Annals of internal medicine 1993, I I 8(7):495-503.

8I. Yamac K, Senol E, Haznedar R: Prophylactic use of fluconazole in neutropenic cancer patients. Postgraduate medical journal 1995 , 7 I (835):284-6.

\section{Pre-publication history}

The pre-publication history for this paper can be accessed here:

http://www.biomedcentral.com/1471-2288/6/40/prepub

\section{Publish with Bio Med Central and every scientist can read your work free of charge}

"BioMed Central will be the most significant development for disseminating the results of biomedical research in our lifetime. "

Sir Paul Nurse, Cancer Research UK

Your research papers will be:

- available free of charge to the entire biomedical community

- peer reviewed and published immediately upon acceptance

- cited in PubMed and archived on PubMed Central

- yours - you keep the copyright
BioMedcentral 